\title{
Transient Exergy Analysis of the Condenser and Evaporator of an Air Source Heat Pump Water Heater
}

\author{
Mehmet Mete Ozturk ${ }^{1}$ and L. Berrin Erbay ${ }^{2}$ \\ 1. Transportation Vocational Sch., Anadolu University, Eskişehir, Turkey \\ 2. School of Eng.and Arch., Eskisehir Osmangazi University, 26480 Batı Meselik, Eskişehir, Turkey
}

\begin{abstract}
In this study the performance of an ASHPWH (air source heat pump water heater) is assessed from exergy point of view in component wise. In order to investigate the work potential of energy, the destruction on the exergy is analyzed and results are summarized for the components individually. The exergy destruction of the system is studied by considering real paths of the pressure and temperature data which are collected during the experiments of the ASHPWH under varying environmental conditions. In the following step, the evolution of the exergy destruction of the system is calculated by a code which is compiled on MATLAB along these temperature and pressure paths. The obtained results reveal the importance of the transient exergy analysis by providing detailed information about exergy destruction of the system such as where it drives up and reaches up to its max and where it drops down and evolves on a smooth path.
\end{abstract}

Key words: Transient exergy analysis, heat pump, condenser, evaporator.

\section{Nomenclature}

$\begin{array}{ll}\dot{m} & \text { mass flow rate }(\mathrm{kg} / \mathrm{s}) \\ \dot{Q} & \text { heat transfer rate }(\mathrm{kW}) \\ \dot{W} & \text { power }(\mathrm{kW}) \\ \dot{E}_{x d} & \text { Exergy destruction }(\mathrm{kW}) \\ \mathrm{h} & \text { specific entahalpy }(\mathrm{kj} / \mathrm{kg}) \\ \mathrm{s} & \text { specific entropy }(\mathrm{kj} / \mathrm{kg} . \mathrm{K}) \\ \psi & \text { flowexergy }(\mathrm{kj} / \mathrm{kg})\end{array}$

\section{Subscripts}

i inlet

o outlet

\section{Introduction}

Heating, cooling and ventilating systems are one of the most important vehicles of our daily lives. By the increase of the importance of the energy efficiency which arises due to diminish of the sources and its global effect on the environment, the studies that focus on the improvement and the investigation of the performance of the systems gain more concern.

Corresponding author: Mehmet Mete Ozturk, Ph.D., research fields: thermodynamics, heat transfer, and shape memory alloys.
Several methods have been in use by the researchers for decades to examine the performance of the systems. Inspection of the capacity of the system from the useful energy point is one other aspect which is widely preferred among the researchers. One common approach in these exergy analyses is to evaluate the system by assuming an ideal change (a quasi steady) between the states which does not allow to consider the real phase change during the process. Even though it provides enough information about the availability of the system, it does not let picture phase change in real since the pressure and temperature change do not follow an ideal path as assumed in quasi-steady cases. In order to get detailed information about the availability change when the system is running, it is necessary to follow the right path of the evolution of these parameters.

In literature the performance analyses of thermal systems mostly depend on the traditional exergy approach which has been reported by various researchers. In all those valuable studies the performance of the heat pumps, absorption heat pumps, air conditioning systems, ground source heat 
pumps are investigated from exergetic point of view either numerically or experimentally [1-11]. Even though these studies enlighten the researchers and reveal the work potential of several systems, it is hard to locate the studies reported the exergy losses at components such as at condenser or evaporator in particular. One of those few examples is reported by Sagia and Paignigiannis [12]. They studied the irreversibilities for vapour compression cycle with refrigerant mixtures R-404A, R-410A, R-410B and $\mathrm{R}-507$ as working fluids and reported exergy losses for the compressor and condenser.

Furthermore in cited studies, the availability of the systems is investigated for a certain state of the process which is typically assumed as the final state of it and exergy of the system is presented for all components with respect to this stage. As given earlier, even though this aspect gives an idea about performance of the components and the whole system, it does not allow understanding the behavior of performance evolution during the entire process. Though the importance of the transient exergy destruction is underlined and revealed by the efforts of some researchers in last few years. One of these studies on this topic is reported by Ozturk and Erbay [13], in which the exergy evolution of an air source heat pump water heater is reported by considering the transient case. In this communication the performance of the system is investigated during the charging time (the period that is necessary to heat the entire water inside the tank) of the heat pump system and the evolution is displayed for the varying environmental conditions as the representative of the different climates that the system is running under. To summarize the results during the charging time leads to a transient solution, which was an important contribution to the literature. In another communication, Jain and Alleyne investigated the transient exergy analysis of a vapor compression system in their study [14]. They derived an expression for the rate of exergy destruction for the refrigerant side dynamics of a VCS (vapour compression system). They summarized the results with respect to time and pointed out importance of the transient solution. In an early study [15] about transient exergy analysis which was reported by Maveety and Razani, an isolated cylindrical thermal system is presented, by applying an integral technique to determine the approximate transient temperature distribution in the system and propose a normalized figure of merit to characterize the optimal exergy extraction ratio.

In this study, performance of a commercial ASHPWH (air source heat pump water heater) is discussed in component wise as an ongoing part of the transient exergy analysis of it. And in particular the goal is to identify the effect of the destruction at the heat exchangers to the overall performance of these systems. The exergy destruction of the system is studied by considering real paths of the pressure and temperature data which are collected during the experiments of the ASHPWH under varying environmental conditions. The different ambient conditions are obtained by the change of temperature and humidity in a climatic room which simulates a diverse environmental condition that the heat pump system is running under. In the following step, the evolution of the exergy destruction of the system is calculated by a code which is compiled on MATLAB along these temperature and pressure paths. The obtained results reveal the importance of the transient exergy analysis by providing detailed information about exergy destruction of the system such as where it drives up and reaches up to its maximum and where it drops down and evolves on a smooth path. That sort of information can guide the researchers about where to focus on to improve the system and how to avoid from such that anomalies. In other words, it may provide to see the big picture of the performance investigations.

\section{System Description}

The air source heat pump water heater used in the 
experiments is provided from a commercial company as a part of the collaboration project. Technical details of the system are given in Table 1 and in the circuit diagram as well in Fig. 1, as it is obvious while the system is running, heat is absorbed at evaporator from air and released at condenser to water.

In order to have a better understanding for the effect of the ambient conditions on the performance of the heat pump, the system is run under different climates which are simulated by climatic chamber as the correspondent of real conditions. Among various environment conditions $5{ }^{\circ} \mathrm{C}, 10{ }^{\circ} \mathrm{C}, 20^{\circ} \mathrm{C}, 30^{\circ} \mathrm{C}$ are chosen as the ambient temperatures along with the humidities are chosen as $70-80-90 \%$ which represent the high humidity where as $40 \%$ humidity represents the poor conditions as regarding the limit reported by Guo et al. [16].

Table 1 Technical properties of ASHPWH.

\begin{tabular}{|l|l|}
\hline Working fluid & R $134 \mathrm{a}$ \\
\hline Water capacity & 300 liter \\
\hline Max. water Temp. & $55^{\circ} \mathrm{C}$ \\
\hline Power source & $220 \mathrm{~V} / 50 \mathrm{~Hz}$ \\
\hline Working conditions & $5-32{ }^{\circ} \mathrm{C}$ \\
\hline
\end{tabular}

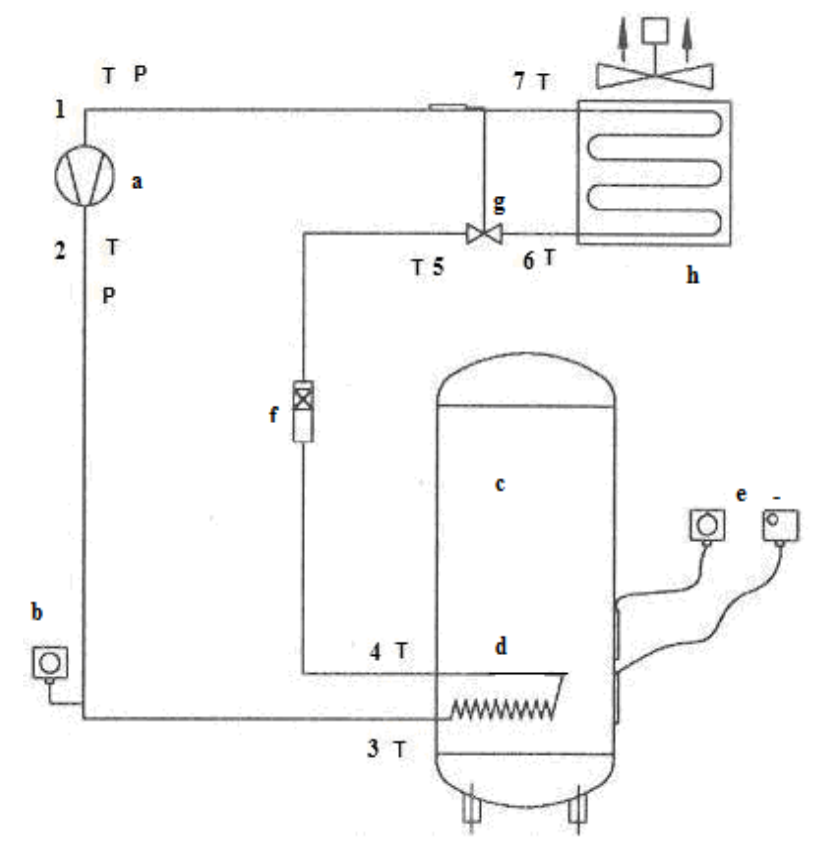

Fig. 1 Circuit diagram of heat pump system: a-compressor; b-high pressure pressostat; c-storage tank; d-condenser; e-thermostat; f-drier filter; e-expansion valve; and $h$-evaporator [13].
The data used in the study are collected from the system at the inlet and outlet of each component which are designated in the schematic of the circuit above. The inlet and outlet of each component is marked by the numbers and by the capitals " $T$ " and "P" in order to represent the assumption made during the calculations as for direction and the sequence of the coolant flow.

The further information about the experiments such as experimental set up, equipments used in the tests, sample size and uncertainty analysis could be found in detail at Ozturk and Erbay’s [13] study.

\section{Theoretical Analysis}

As given in the previous sections, the performance of the air source heat pump water heater is examined from the exergy point of view in order to demonstrate the quality of the stream in the system. The calculations are accomplished as regarding to the data collected during the tests that are carried out inside a climatic chamber. As a further step, the evolution of the exergy destruction of the system is calculated by a code which is compiled on MATLAB along the temperature and pressure paths obtained.

The following assumptions have been made during the analysis.

- System is steady state steady flow;

- Kinetic and potential effects are negligible;

- The directions of heat transfer to the system and work transfer from the system are positive;

- Heat transfer and refrigerant pressure drops in tubing between the components are ignored;

- Air is an ideal gas with constant specific heat;

- Power consumption of the fan is neglected when compared with the power consumption of compressor;

- Dead states are the environmental condition under consideration;

- Heat loss through the isolated storage surface is neglected.

\subsection{Conservation Equations Applied to the System}

The necessary conservation equations for the exergy analysis are summarized in the following [13]. 


\subsubsection{Conservation of Mass}

Conservation equation of the mass at each component is given as

$$
\sum \dot{\mathrm{m}}_{1}=\sum \dot{\mathrm{m}}_{\mathrm{o}}
$$

where, $\dot{\mathrm{m}}$ is the mass flow rate, and subscripts "I" and "o" represents inlet and outlet, respectively.

\subsubsection{Conservation of Energy}

As regard to first law of thermodynamics energy can be neither created nor destroyed.

$$
E_{i}=E_{o}
$$

This approach can be rewritten with regard to the net energy transfer which relies on the balance of the net heat, work and mass transfer in and out of a control volume as in the following.

$$
\begin{aligned}
& \dot{\mathrm{Q}}_{\mathrm{cv}}+\dot{\mathrm{m}}_{\mathrm{l}}\left(\mathrm{h}_{\mathrm{i}}+\frac{1}{2} \dot{\mathrm{V}}_{\mathrm{i}}+\mathrm{gZ} \mathrm{Z}_{\mathrm{i}}\right)= \\
& \dot{\mathrm{m}}_{\mathrm{o}}\left(\mathrm{h}_{\mathrm{o}}+\frac{1}{2} \dot{\mathrm{V}}_{\mathrm{o}}+\mathrm{gZ}\right)+\dot{\mathrm{W}}_{\mathrm{cv}}
\end{aligned}
$$

where, $\dot{Q}$ is the heat rate, $\dot{W}$ is the power, $\dot{m}$ mass flow rate, $\mathrm{h}$ is entalpy, $\dot{V}$ is speed, $g$ is gravity, $\mathrm{Z}$ is height.

In order to cover the quality of an operating system, the second law of thermodynamics should be considered. The entropy change in a steady state steady flow process is summarized as; the sum of the entropy generation from the irreversibility's within system boundary, the net entropy transfer through the control volume by heat transfer and entropy change by mass flow across the boundaries which is also given below

$$
\dot{\mathrm{S}}_{\text {gen }}=\dot{\mathrm{m}}_{0} \mathrm{~S}_{0}-\dot{\mathrm{m}}_{\mathrm{i}} \mathrm{S}_{\mathrm{i}}-\frac{\dot{\mathrm{Q}}_{\mathrm{cv}, \mathrm{k}}}{\mathrm{T}_{\mathrm{K}}}
$$

\subsubsection{Exergy Balance Equation}

The exergy balance at steady state condition is usually described as the balance between the net exergy transfer by heat, work or mass flow through the boundaries of control volume and destructed exergy as noted in the following,

$$
\begin{gathered}
\sum\left(1-\frac{\mathrm{T}_{0}}{\mathrm{~T}}\right) \dot{\mathrm{Q}}_{\mathrm{cv}, \mathrm{k}}-\dot{\mathrm{W}}_{\mathrm{cv}}+\dot{\sum} \dot{\mathrm{m}}_{\mathrm{ln}} \psi_{\mathrm{ln}}- \\
\sum \dot{\mathrm{m}}_{\text {out }} \psi_{\text {out }}=\dot{\mathrm{E}}_{\mathrm{xd}}
\end{gathered}
$$

where,

$$
\psi=\left(\mathrm{h}-\mathrm{h}_{0}\right)-\mathrm{T}\left(\mathrm{s}-\mathrm{s}_{0}\right)
$$

\subsubsection{Exergy Analysis of the System}

In the light of the exergy description given above, the exergy balance equation can be rewritten for each component independently with respect to their individual conditions.

For compressor

$$
\begin{gathered}
\dot{\mathrm{m}}_{1}=\dot{\mathrm{m}}_{2}=\dot{\mathrm{m}}_{\text {ref }} \\
\dot{\mathrm{W}}_{\text {comp }}=\dot{\mathrm{m}}_{\text {ref }}\left(\mathrm{h}_{2 \text { act }}-\mathrm{h}_{1}\right) \\
\dot{\mathrm{E}}_{\mathrm{xd}, \mathrm{comp}}=\dot{\mathrm{m}}_{\text {ref }}\left(\psi_{1}-\psi_{2, \text { act }}\right)+\dot{\mathrm{W}}_{\text {comp }}
\end{gathered}
$$

For condenser

$$
\begin{gathered}
\dot{\mathrm{m}}_{3}=\dot{\mathrm{m}}_{4}=\dot{\mathrm{m}}_{\mathrm{ref}} \\
\dot{\mathrm{Q}}_{\text {cond }}=\dot{\mathrm{m}}_{\text {ref }}\left(\mathrm{h}_{3 \mathrm{act}}-\mathrm{h}_{4}\right) \\
\mathrm{Q}_{\text {cond }}=\mathrm{Q}_{\text {water }}=\mathrm{M}_{\mathrm{w}} \mathrm{C}_{\mathrm{p}, \mathrm{w}} \frac{\mathrm{dT}}{\mathrm{dt}} \\
\dot{\mathrm{E}}_{\mathrm{xd}, \text { cond }}=\dot{\mathrm{m}}_{\text {ref }}\left(\psi_{3, \text { act }}-\psi_{4}\right)-\dot{\mathrm{Q}}_{\mathrm{w}}\left(1-\frac{\mathrm{T}_{0}}{\mathrm{~T}_{\mathrm{w}}}\right)
\end{gathered}
$$

For expansion valve

$$
\begin{gathered}
\dot{\mathrm{m}}_{5}=\dot{\mathrm{m}}_{6}=\dot{\mathrm{m}}_{\mathrm{ref}} \\
\mathrm{h}_{5}=\mathrm{h}_{6} \\
\dot{\mathrm{E}}_{\mathrm{xd}, \exp }=\dot{\mathrm{m}}_{\mathrm{ref}}\left(\psi_{5}-\psi_{6}\right)
\end{gathered}
$$

For evaporator

$$
\begin{gathered}
\dot{\mathrm{m}}_{6}=\dot{\mathrm{m}}_{7}=\dot{\mathrm{m}}_{\mathrm{ref}} \dot{\mathrm{m}}_{8}=\dot{\mathrm{m}}_{9}=\dot{\mathrm{m}}_{\mathrm{air}} \\
\dot{\mathrm{Q}}_{\text {evap }}=\dot{\mathrm{m}}_{\mathrm{ref}}\left(\mathrm{h}_{7}-\mathrm{h}_{6}\right) \\
\dot{\mathrm{Q}}_{\text {evap }}=\dot{\mathrm{Q}}_{\mathrm{fan}}=\dot{\mathrm{m}}_{\text {air }} \mathrm{C}_{\mathrm{p}^{\prime} \text { air }}\left(\mathrm{T}_{8}-\mathrm{T}_{9}\right) \\
\dot{\mathrm{E}}_{\mathrm{xd} \text {,evap }}=\dot{\mathrm{m}}_{\mathrm{ref}}\left(\psi_{6}-\psi_{7}\right)+\dot{\mathrm{m}}_{\text {air }}\left(\psi_{8}-\psi_{9}\right)
\end{gathered}
$$

The evolution of exergy destruction of the system in component wise is calculated with respect to time according to the values collected during the test.

The exergy analysis of the system is investigated from exergy destruction point of view during the heating time of the water inside the tank. From this aspect, the intention is not only to reveal the effect of the ambient conditions on the system performance but also to see the evolution of the exergy simultaneously 
by time. This approach will provide to understand the characteristics of the exergy change during the heating process and to see which component has the most influence on the systems availability.

\section{Results and Discussion}

The results given in this section are presented with regard to time that is necessary to heat up the water from $15{ }^{\circ} \mathrm{C}$ to $55{ }^{\circ} \mathrm{C}$ under different environment conditions. As it is expected, colder the environment longer the heating period. The period of time needed to warm up the water under varying ambient conditions, which are demonstrated in Table 2.

As it is obvious from the tables, the entire water inside the tank is warmed up to the target temperature quicker at the better ambient conditions while it gets worse for the poor conditions. Furthermore, it could be worthy to note that, the duration has a direct effect on performance of the system since it is a measure of energy consumption. With regard to that aspect, it could be said that, shorter the heating period of time, higher the performance.

As described earlier in detail, in order to bring a more realistic approach to exergy analysis of the system, the actual pressure and temperature paths are followed. The necessary data are collected during the heating time in each ambient condition. As the further step, data are processed and transient exergy analysis is calculated by a code which is compiled by MATLAB. For detailed information about the code, the reader is referred to the earlier paper by the authors [13].

The purpose of the cited the study [13] was to evaluate the performance of the air source heat pump water heater. The classical approach is also acknowledged and the figure pertaining to this aspect is displayed in the mentioned study as well. The very common definition of the performance of the heat pump systems is the ratio of heat transfer carried out through the process to the power consumption of this process.
Table 2 The necessary time to heat the water from $10{ }^{\circ} \mathrm{C}$ to $55^{\circ} \mathrm{C}$ at different ambient temperatures .

\begin{tabular}{ll}
\hline Temperature $\left({ }^{\circ} \mathrm{C}\right)$ & Heating time $(\mathrm{h})$ \\
\hline 30 & 5 \\
20 & 7.5 \\
10 & 11 \\
5 & 12 \\
\hline & $\mathrm{COP}=\frac{\dot{\mathrm{Q}}}{\dot{\mathrm{W}}}$
\end{tabular}

where, $\dot{Q}$ is the heat rate, $\dot{W}$ is the power.

In Fig. 2, the performance of the system gets its lowest value at the poor weather conditions and drives up when the ambient temperatures gets higher as it expected. In addition, it is clearly seen from the figure that, the high humidity directly affects the performance of the system at low ambient temperatures as a reason of frost on evaporator that prevents heat transfer through it.

In this particular study, a closer look to the heat exchangers', including both the condenser and evaporator, exergy destruction will be taken. The results will be demonstrated from transient exergy destruction point of view which determined along temperature and pressure path attained during the tests.

The exergy destruction change is presented with respect to time which is the correspondent of the period that is needed to warm up the entire water inside tank. As it could be seen and summarized previously in earlier section in Table 2, they differ from ambient condition to ambient condition. The

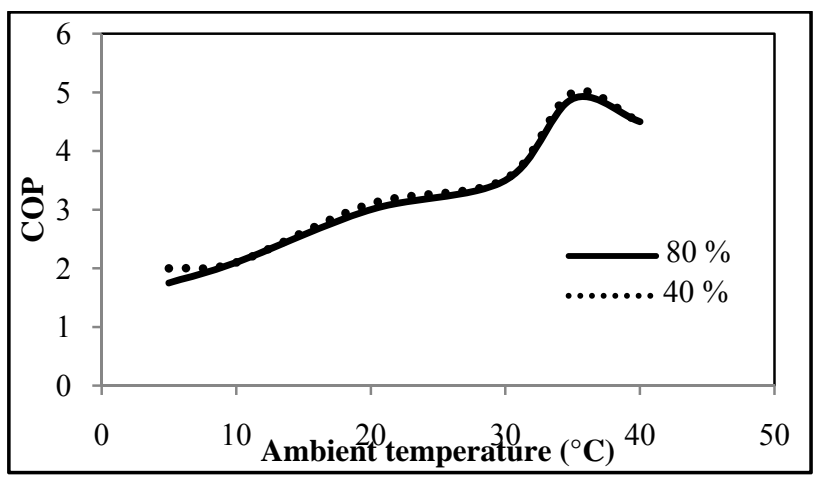

Fig. 2 Variation of system performance with respect to the ambient temperature [13]. 


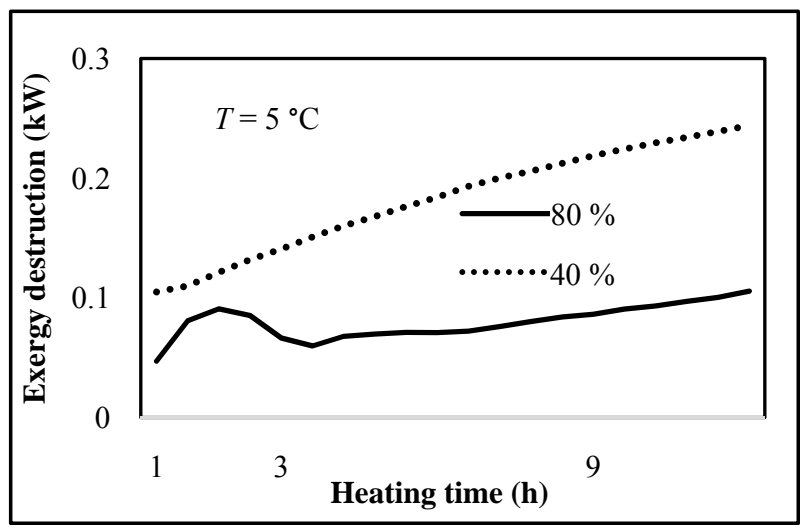

(a)

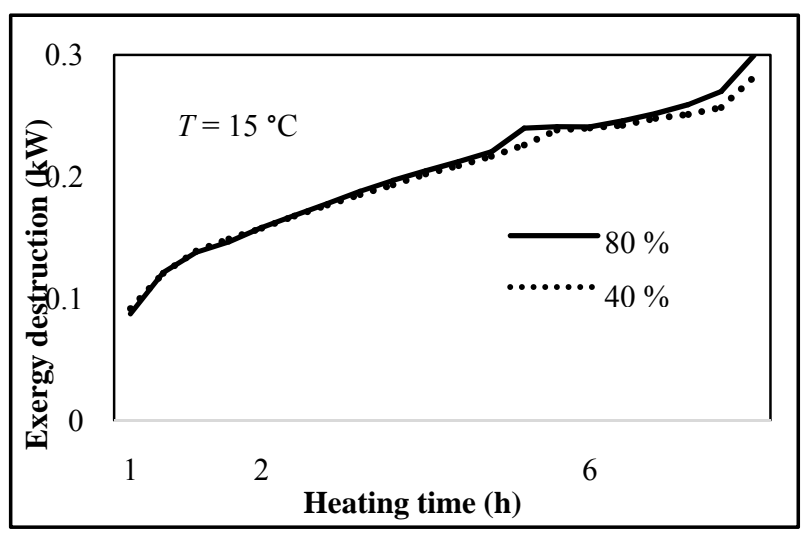

(c)

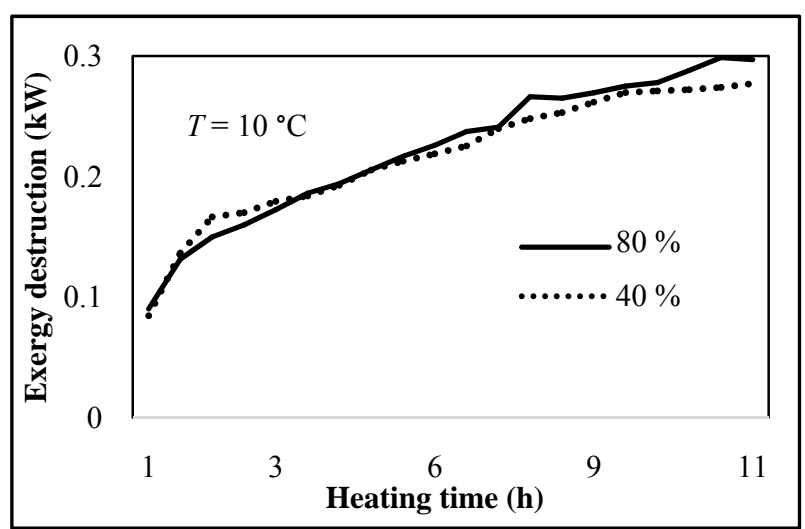

(b)

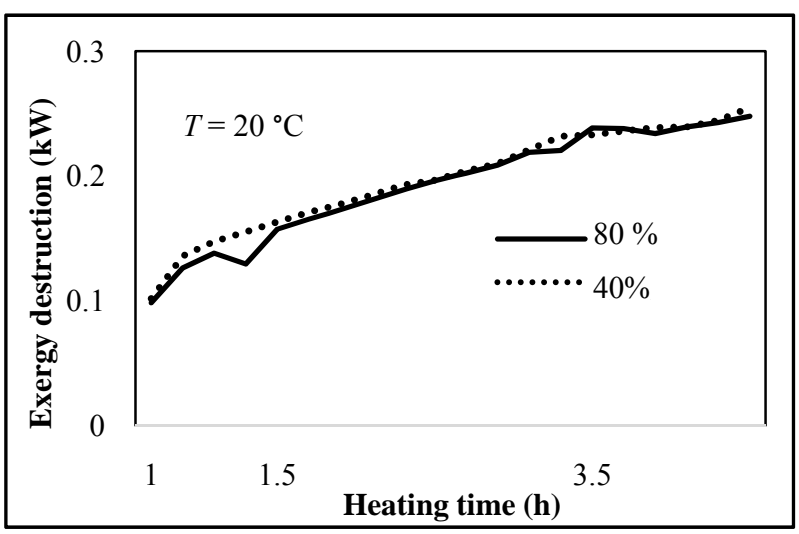

(d)

Fig. 3 The evolution of condenser's exergy destruction by time for humidity's $40 \%$ and $80 \%$ : (a) at $5{ }^{\circ} \mathrm{C}$ ambient temperature; (b) at $10{ }^{\circ} \mathrm{C}$ ambient temperature; (c) at $20^{\circ} \mathrm{C}$ ambient temperature; and (d) at $30{ }^{\circ} \mathrm{C}$ ambient temperature.

results are displayed for each environment temperature individually and the effect of humidity in each case is investigated between the humidity's $40 \%$ and $80 \%$.

Figs. 3a-3d summarize the exergy destruction in condenser by time. The evolution of the exergy destruction is presented for each temperature condition individually during their own heating period of times. The destruction keeps drive up during the entire run of the system. The only exception of this appeared as the poorest environment condition which is shown in Fig. 3a. As it can be seen, the destruction raises and reaches up to a maximum value at the earlier part of heating and drops down for a short period of time and again drives up after the formation of vague knee. Even though it tends to rise up, the final point that it could reach, is bellow the other curve which is the representative of the humidity condition $40 \%$. The reason of this bizarre evolution relies on the formation of the ice emerged at evaporator due to poor environment condition where humidity is $80 \%$ and temperature $5{ }^{\circ} \mathrm{C}$. As for the remaining graphs, exergy destruction's trend increases by the time and reaches to its maximum at the end of the process which seems independent from the humidity of the test environment. And two curves pertain to humidity's in each temperature diagram merely differ from each other. Among the figures, it is obvious that, the higher exergy destruction rates are observed for the warmer ambient conditions while the lowest trend is examined at the poorest condition. That is because, the lower the temperature is, the lower the enthalpy value as for the corresponding coolant temperature during the cycle. With regard to the ice formed on the evaporator, the enthalpy gets its lower value which leads to lower 


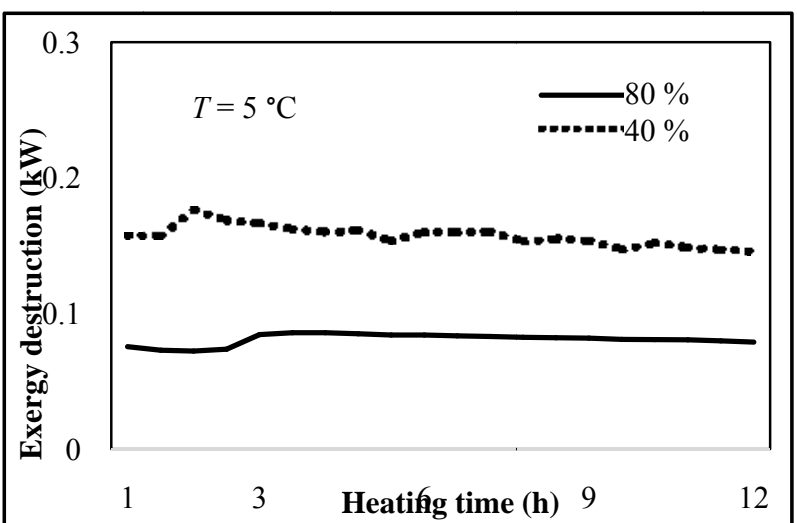

(a)

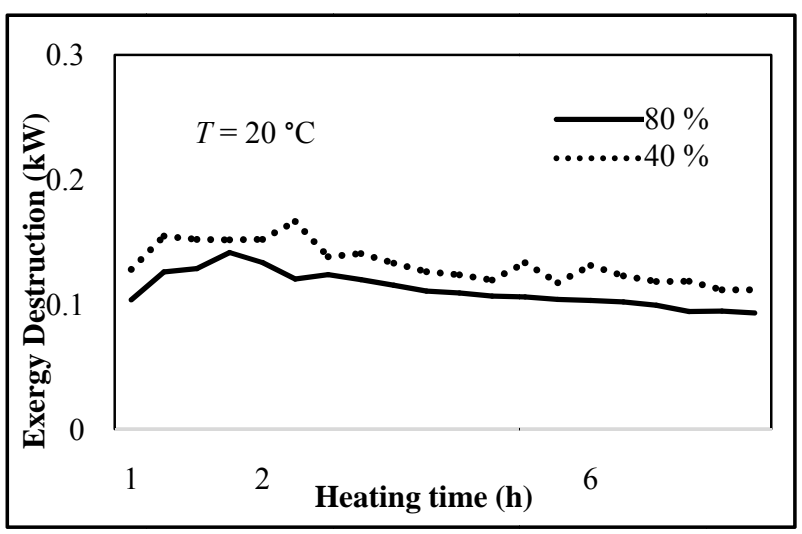

(c)

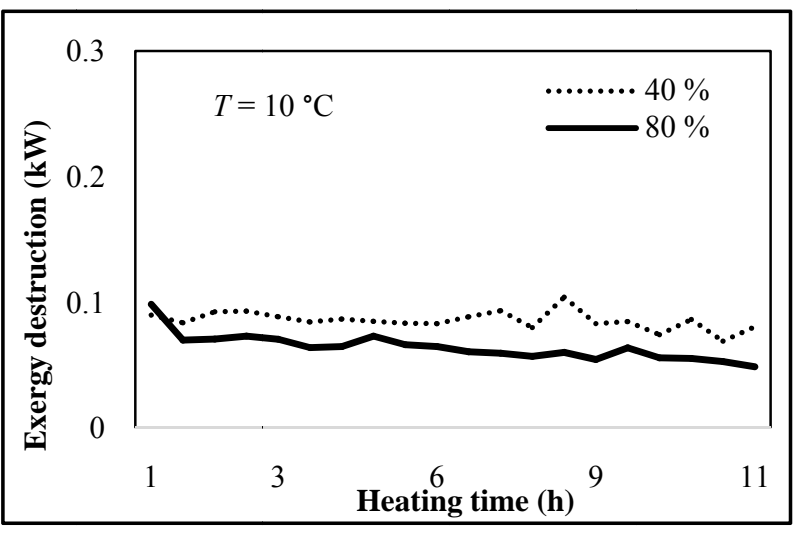

(b)

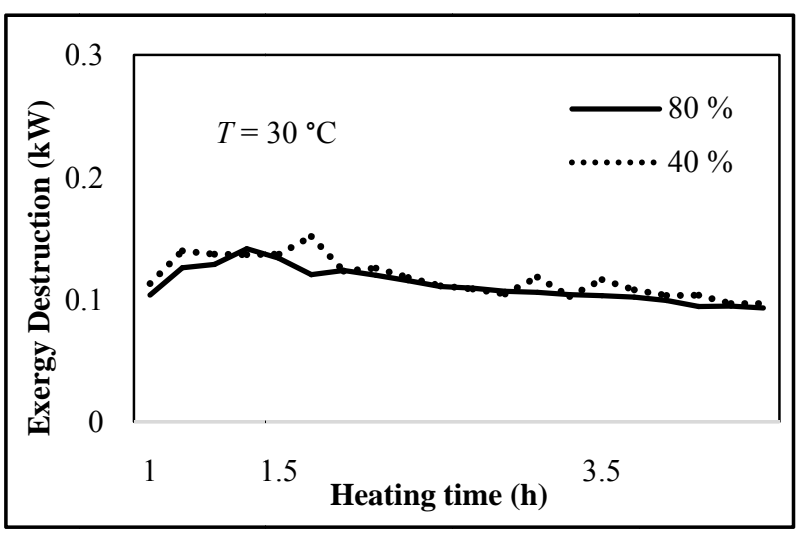

(d)

Fig. 4 The evolution of evaporator's exergy destruction by time for humidity's $40 \%$ and $80 \%$ : (a) at $5{ }^{\circ} \mathrm{C}$ ambient temperature; (b) at $10{ }^{\circ} \mathrm{C}$ ambient temperature; (c) at $20^{\circ} \mathrm{C}$ ambient temperature; and (d) at $30{ }^{\circ} \mathrm{C}$ ambient temperature.

exergy destruction values in the calculations summarized earlier. But at this point, it should be reminded once again that, even though the exergy destructions over the heating period seem like having similar trends, each environment condition has different heating period of time. When the ambient gets warmer, period gets shorter, so the longer operation time leads to higher energy loses during a single run of system which is summarized in Table 2.

A similar investigation is performed for the evaporator as well. The schemes for different ambient conditions are given individually in a comparison between different humidity conditions chosen for the experiments (Figs. 4a-4d). The humidity does not have an influence at warmer ambient like $10^{\circ} \mathrm{C}, 20^{\circ} \mathrm{C}$ and $30^{\circ} \mathrm{C}$ as in the cooler ambient $\left(5^{\circ} \mathrm{C}\right)$. The bigger impact can be observed at $5^{\circ} \mathrm{C}$ where the ice begins to emerge over the fins of the evaporator. As it can be predicted, the ice layer prevents the heat transfer from air to coolant at evaporator which causes to performance decline. Among the figures, the highest destruction value and highest trend can be detected at the coolest environment as well.

Even though the destruction trend is looking like straight in all curves in all conditions, the slight drop tendency could be caught. However this change from the begging of the heating operation to the end is not as obvious as in condenser. Like the destruction evolution at condenser, due to the heat transfer blockage at the poorest environment condition, the exergy destruction curve for the $5{ }^{\circ} \mathrm{C}$ with $80 \%$ gets worsen. The cause of this unexpected change relies on the same reason as explained for Fig. 3 which is, lower temperature tends to lower the enthalpy value as 
for the corresponding coolant temperature during the cycle.

Furthermore, unlike the condenser's exergy destruction evolution, there is a more noticeable difference between the varying humidity's $(40 \%, 80 \%)$ in all three environment temperatures $\left(5^{\circ} \mathrm{C}, 10{ }^{\circ} \mathrm{C}\right.$, $\left.20^{\circ} \mathrm{C}\right)$. The only exception of this can be seen at the final temperature $\left(30^{\circ} \mathrm{C}\right)$ in which the curves are about to overlap. The destruction difference between the curves approaching to each while the environment gets warmer. Again in this group of diagram, it is necessary to remind the difference of the heating times which have an impact on the overall performance evaluation of the component. In order to understand the overall loss of the system, it is very crucial to consider the period of time in each individual case.

\section{Conclusions}

In this study, the performance of an air source heat pump water heater is assessed from exergy point of view in component wise. In order to investigate the work potential of energy, the destruction on the exergy is analyzed and results are summarized for the components individually. In this particular communication the destructions on the heat exchangers are examined and results are demonstrated with respect to time. The transient exergy analyses of these components are introduced during the heating period of time. By this approach, it is aimed to provide enough information to see the big picture of exergy destruction in an entire process of this kind of systems. In order to have a more realistic approach to these types of problems a series of tests had been carried out. Four different ambient temperatures $\left(5^{\circ} \mathrm{C}\right.$, $10^{\circ} \mathrm{C}, 20^{\circ} \mathrm{C}$ and $30^{\circ} \mathrm{C}$ ) and two different humidities $(40 \%$ and $80 \%)$ are chosen for the experiments. The experiments are carried out in a climatic chamber which controls the humidity and temperature during the entire heating process. Meanwhile the temperature and pressure data at the inlet and outlet of the components are collected. And finally the analyses are carried out by a code which is compiled in MATLAB with regard to the data collected.

By looking at the presented results, it can be said that, performance of the system gets worse when the ambient temperature gets colder. The longer heating period of time is the first reason of this interpretation, which tends to destruct more potential work. The second one is the decrement on the heat amount that could transfer to the working fluid. Within the shared results it can be noted that, among the heat exchangers, destruction at the evaporator is more stable than at the condenser since the exergy destruction drives up during the whole period even for the poorest ambient conditions. That is because of the increasing temperature difference between the coolant and the ambient temperatures which is air on one side and water on the other side. From this aspect it will not be so wrong to say the condenser has more impact on the loss of work potential among the heat exchangers. As a future study, the integration of the exergy destruction over the heating time will be carried out for the entire system in order to maintain a more realistic approach to the real exergy destruction.

\section{References}

[1] Alexis, G. K. 2005. "Exergy Analysis of Ejector-Refrigeration Cycle Using Water as Working Fluid." Internatıonal Journal of Energy Research 29: 95-105.

[2] Bonnet, S., Alaphilippe M., and Stouffs, P. 2005. "Energy, Exergy and Cost Analysis of a Micro-cogeneration System Based on an Ericsson Engine." International Journal of Thermal Sciences 44: 1161-8.

[3] Chengqin, R., Nianping, L., and Guangf, T. 2002. "Principles of Exergy Analysis in HVAC and Evaluation of Evaporative Cooling Schemes." Building and Environment 37: 1045-55.

[4] Hepbasli, A., and Akdemir, O. 2004. "Energy and Exergy Analysis of a Ground Source (Geothermal) Heat Pump System." Energy Conversion and Management 45: 737-53.

[5] Hussain, M. M., Dincer, I., and Li, X. 2004. "Energy and Exergy Analysis of an Integrated SOFC Power System." CSME 2004 Forum 1080-1090. 
[6] Lior, N., and Zhang, N. 2007. "Energy, Exergy and Second Law Performance Criteria." Energy 32: 281-96.

[7] Nikolaidis, C., and Probert, D. 1998. "Exergy-Method Analysis of a Two-Stage Vapour-Compression Refrigeration-Plants Performance." Applied Energy 60: 241-56.

[8] Han, X. H., Wang, Q., Zhu, Z. W., and Chen, G. M. 2007. "Cycle Performance Study on R32/R125/R161 as an Alternative Refrigerant to R407C." Applied Thermal Engineering 27: 2559-65.

[9] Feng, C., Kai, W., Shouguo, W., Ziwen, X., and Pengcheng, S. 2008. "Investigation of the Heat Pump Water Heater Using Economizer Vapor Injection System and Mixture of R22/R600a." International Journal of Refrigeration, 1-6.

[10] Razani, A., Roberts, T., and Flake, B. 2007. "A Thermodynamic Model Based on Exergy Flow for Analysis and Optimization of Pulse Tube Refrigerators." Cryogenics 47: 166-73.

[11] Zhiqiang, L., Xiaolin, L., Hanqig, W., and Wangming, P. 2008. "Performance Comparison of Air Source Heat Pump with R407C and R22 under Frosting and
Defrosting." Energy Conversion and Management 49: 232-39.

[12] Stegou-Sagia, A., and Paignigiannis, N. 2003. "Exergy Losses in Refrigerating Systems. A Study for Performance Comparisons in Compressor and Condenser." International Journal of Energy Research 27 (12): 1067-78.

[13] Ozturk, M. M., and Erbay, L. B. 2012. “An Experimental Analysis of Air Source Heat Pump Water Heater." J. of Thermal Science and Technology 32 (1): 117.

[14] Jain, N., and Alleyne, A. 2014. "Transient Exergy Destruction Analysis of a Vapor Compression System." International Refrigeration and Air Conditioning Conference, paper 1542.

[15] Maveety, J. G., and Razani, A. 1996. "Transient Exergy Analysis and Optimal Removal Time of a Cylidircal Storage System." Journal of Propulsion and Power 12 (2): 420-3.

[16] Guo, X., Chen, Y., Wang, W., and Chen, C. 2008. "Experimental Study on Frost Growth and Dynamic Performance of Air Source Heat Pump System." Applied Thermal Engineering 28: 2267-78. 